\title{
Aspectos culturais em um dicionário pedagógico
}

Paola Baccin (USP)

Universidade de São Paulo

pbaccin@usp.br

Resumo: Nesta apresentação objetiva-se apresentar alguns dos resultados de uma pesquisa que verificou o papel das informações de caráter cultural e o tratamento dessas informações em um dicionário pedagógico bilíngue. $\mathrm{Na}$ aula de língua, entre as várias ferramentas de que dispõe o professor, duas têm caráter mais permanente e exigem um investimento financeiro mais significativo por parte dos alunos: o livro didático e o dicionário, sendo o dicionário a ferramenta que conduz o aluno à autonomia e que, mesmo ao final do curso, continuará a ser uma fonte de consulta. Para o público, para os profissionais do idioma, para o aluno já formado e que atua no mercado de trabalho como especialista há uma grande variedade de dicionários, resultado de longa tradição lexicográfica. Observa-se também que, no sentido da compreensão, o aluno conta com várias ferramentas, inclusive em formato eletrônico. No sentido da produção textual, no entanto, constata-se que há uma lacuna e é nessa direção que acreditamos poder contribuir a partir da elaboração de um dicionário específico para a produção de textos em língua italiana. O dicionário para aprendizes não pode prever todos os ruídos de comunicação entre falantes de duas línguas, mas, ao apresentar alguns modelos, explicita as diferenças, informa o aluno sobre a existência de dificuldades, colabora para a formação do seu repertório cultural e aumenta a sua competência comunicativa intercultural.

Palavras-chave: Cultura. Dicionário pedagógico. Dicionário bilíngue. Produção textual.

Abstract: In questa presentazione si pretende di presentare alcuni dei risultati di una ricerca que ha verificato il ruolo delle informazioni di carattere culturale e il trattamento delle informazioni in un dizionario pedagogico bilingue. Nella lezione di lingua, tra i vari strumenti a disposizione del professore, due hanno carattere più permanente e richiedono un investimento finanziario più significativo da parte degli studenti: il manuale didattico e il dizionario, essendo il dizionario lo strumento che conduce l'alunno all'autonomia che, anche alla fine del corso, continuerà ad essere fonte di consultazione. Al pubblico, ai professionali di lingue, allo studente già laureato e che attua nel mercato di lavoro come specialista esiste una grande varietà di dizionari, risultato di lunga tradizione lessicografica. Si osserva inoltre che, 
nel senso della comprensione, lo studente conta su vari strumenti, inclusi quelli in formato elettronico. Nel senso della produzione testuale, però, si osserva che vi è un divario ed è in questa direzione che crediamo di poter contribuire con l'elaborazione di un dizionario specifico per la produzione di testi in lingua italiana. Il dizionario per apprendisti non può prevedere tutti i rumori di comunicazione tra parlanti di due lingue, ma, presentando alcuni modelli, esplicita le differenze, informa lo studente sull'esistenza di difficoltà, colabora per la formazione del suo repertorio culturale e aumenta la sua competenza comunicativa interculturale.

Key words: Cultura. Dizionario pedagogic. Dizionario bilingue. Produzione testuale.

\section{Introdução}

O mundo é um continuum que cada sociedade recorta de acordo com a sua necessidade sociocultural e denomina as partes recortadas de acordo com o seu sistema linguístico. O lexicógrafo é um "arrumador", que busca pôr ordem no caos e chamar cada coisa pelo seu nome e ao lexicógrafo bilíngue cabe a tarefa de se debruçar sobre o problema da equivalência entre os nomes escolhidos em cada cultura.

O dicionário pedagógico bilíngue (tanto voltado para a compreensão de textos, quanto para a produção) visa elucidar as dúvidas do aprendiz e auxiliá-lo na aquisição do léxico em língua estrangeira. Um dicionário pedagógico bilíngue se distingue dos demais porque deve incluir uma série de informações úteis ao aluno de língua estrangeira, que para um tradutor e para o público em geral são supérfluas.

O dicionário pedagógico com vistas à produção tem duas funções primordiais, e ambas devem receber um tratamento adequado, de forma que uma não prejudique a outra: em primeiro lugar, deve responder de forma imediata às dúvidas de léxico durante a produção textual; em segundo lugar, deve fornecer informações lexicográficas complementares para ajudar o aluno-consulente na escolha do equivalente mais adequado.

A equivalência, por exemplo, entre $<$ casa $>$ (português) e $<$ casa $>$ (italiano) está no sema: moradia. No entanto, as soluções de moradia de cada cultura diferem, desde o aspecto da habitação, da quantidade e da utilidade de cada cômodo, até a quantidade e a escolha dos móveis e utensílios. Ao descobrir essas diferenças apenas no momento de inserção no outro 
país (por motivo de turismo, de estudo, de trabalho), o aluno, ao constatar que elas existem, pode experimentar um estranhamento capaz de gerar barreiras na comunicação e na aceitação dessas diferenças.

A competência comunicativa intercultural, considerada como a capacidade de compreender e de interagir de maneira efetiva com pessoas de diferentes origens culturais, permite que se estabeleça um diálogo entre as duas culturas, prevenindo os ruídos na comunicação. O aluno-consulente de um dicionário bilíngue que contemple aspectos interculturais terá acesso a dados sobre a outra cultura e poderá compreender que as duas realidades são apenas diferentes, nem superiores, nem inferiores uma à outra e, assim, aperfeiçoar a sua competência comunicativa intercultural.

Consideramos que cultura é um sistema adquirido e compartilhado de crenças e valores que determinam hábitos, regras, conhecimentos e tudo o que distingue o modo de vida de um grupo social. Cultura é, também, a manifestação dessas crenças, valores, hábitos, regras e conhecimentos em expressões artísticas que podem compor a "alta cultura" e a "cultura popular". E, por fim, cultura é o sistema comunicativo compartilhado entre os integrantes de determinado grupo social.

A cultura é aprendida, adquirida e compartilhada sempre dentro de um grupo, que começa no microgrupo que pode ser o núcleo familiar (primeira socialização) e se amplia em outros grupos (segunda socialização), até o macrogrupo que inclui toda a humanidade. Assim, entre dois países SEMPRE haverá inegáveis diversidades culturais, já que a diversidade é uma das características inerentes aos seres.

Considerar a cultura como um sistema implica dizer que se um dos elementos é modificado, todo o conjunto se modifica, ou seja, em uma situação de culturas em contato todos os envolvidos se modificam. Todas as situações de socialização e de contatos interculturais implicam em uma modificação do sistema e o ser humano, ao longo da vida, inevitavelmente é modificado e modifica os grupos culturais aos quais pertence, em um movimento constante.

A cultura é adquirida ao longo da vida de duas maneiras: por meio da observação e da imitação e por meio da educação formal. Um aluno de língua estrangeira está inserido em um contexto de educação formal que é um "treinamento para inserção e comunicação em um grupo social" diferente do seu grupo de origem. Além das informações oferecidas pelo livro Revista Italiano UERJ 
didático, pelos filmes e materiais autênticos oferecidos pelo professor, o aluno aprende também pela observação e pela imitação dos modelos. O modelo mais próximo é o próprio professor (nativo ou não) e todos os falantes nativos com os quais terá contato em situações comunicativas. Oferecer ao aluno instrumentos para que compreenda que algumas atitudes, modos de agir e de interagir são frutos de um sistema cultural, contribuirá para a formação de sua competência comunicativa intercultural, ou seja, o aluno consciente saberá ponderar as escolhas culturais da cultura em contato e terá mais instrumentos para superar um eventual choque cultural.

Todas as possibilidades de enfoque para o estudo dos aspectos culturais oferecem uma importante contribuição também para os estudos do léxico, sobretudo para a lexicografia pedagógica e vice-versa, em outras palavras, a lexicologia e a lexicografia oferecem alguns pressupostos teóricos, instrumentos e metodologias que podem contribuir para a compreensão das diferenças culturais.

Apresentamos a seguir, alguns resultados obtidos em nossa pesquisa de pós-doutorado na qual fizemos um levantamento sobre aspectos culturais de brasileiros e italianos sobre o campo semântico da habitação e da alimentação. Para coletar as informações sobre o campo semântico da habitação, foram elaborados e aplicados consecutivamente três instrumentos: questionários abertos; depoimentos de italianos que moram no Brasil e um questionário eletrônico, totalizando 576 documentos. Os depoimentos são numerados de acordo com o registro que pode ser verificado em nossa tese de livre-docência (cf. Baccin, 2012).

\section{As inferências automáticas e a comunicação intercultural}

A linguagem é ambígua por natureza: não apenas no nível da palavra, mas também no nível da frase e até mesmo do discurso. As inferências sobre os significados de palavras, sentenças e discursos são feitas a partir da própria visão de mundo e tendem a ser fixas, não são tentativas, ou seja, em um contexto comunicativo, assume-se que aquilo que está sendo dito está de acordo com o próprio conhecimento de mundo. Se nada nos alerta de que essa normalidade está sendo quebrada ou alterada, as conclusões serão sempre as mesmas. Nossas inferências são feitas muito rapidamente, sobretudo, quando a comunicação está sendo realizada entre indivíduos que compartilham o mesmo grupo cultural. (SCOLLON, SCOLLON e JONES, 2012 p. 10-16) 
Quando um italiano diz que "fez uma faxina completa e limpou a cozinha e o banheiro", um interlocutor brasileiro infere que nessa tarefa tenham sido usados produtos de limpeza, escovas, um balde (e/ou uma vassoura), muita água e que havia um ralo para onde se pudesse puxar a água com um rodo:

Quando estive na Itália, no apto onde morei com amigos não tinha ralo no banheiro, quando fui lavá-lo a $1^{\text {a }}$ vez (a moda brasileira, isto é, com bastante água) me dei conta que não tinha como escoá-la, foi um sufoco! (informante brasileiro $n^{\circ} 311$ )

Um italiano por sua vez, infere que um brasileiro tenha usado um moccio ou um pano de chão e produtos de limpeza:

$\begin{array}{ll}\text { La presenza, nei bagni e in genere nella } & \text { A presença, nos banheiros e, geralmente } \\ \text { lavanderia, di scoli per l'acqua ("ralos"), veri } & \text { na lavanderia, de ralos para a água, } \\ \text { e propri buchi nei quali far scorrere l'acqua } & \text { verdadeiros buracos pelos quais se faz } \\ \text { che veniva lanciata abbondantemente sul } & \text { escorrer a água que era jogada, em } \\ \text { pavimento per pulirlo (anche qui, che } & \text { abundância, no chão para lavá-lo (mais } \\ \text { spreco!), invece che economicamente attinta } & \text { uma vez, que desperdício!). Na Itália, a } \\ \text { da un secchio con lo straccio, come in Italia. } & \text { água é extraída economicamente de um } \\ \text { (informante italiano } n^{\circ} \text { ) } & \text { balde, com um pano de chão. }\end{array}$

A ambiguidade das palavras tem sua origem no nível extralinguístico. O dicionário Houaiss (2009) nos informa que "toalha é uma peça de linho, algodão etc., para enxugar as mãos, o rosto ou todo o corpo e cita como exemplos a toalha de mãos; a toalha de rosto e a toalha de banho".

Um aluno brasileiro de italiano, com uma razoável competência linguística, saberá que $<$ tovaglia $>$ e $<$ toalha $>$ são falsos amigos e que o correspondente em italiano para a definição acima é <asciugamano $>$. Em uma situação comunicativa, ao solicitar <asciugamani $>$ em um hotel, receberá três peças: uma toalha grande, uma média e outra pequena. Pelo seu conhecimento de mundo, atribuirá os seguintes nomes às peças recebidas: toalha de banho, toalha de rosto e toalha de mão. Na verdade, a toalha menor é uma toalha para o bidê (para a higiene íntima).

Curiosamente a toalha para bidê é chamada <ospite>, ou seja, teria a mesma função da toalha de mão no Brasil. A dúvida sobre a denominação causa estranhamento também aos italianos. Um diálogo extraído de um site de perguntas e respostas confirma essa observação:

Pergunta: Mas, por que o asciugamanino da bidè é chamado ospite? Não entendo por que devemos oferecer às visitas uma toalhinha de bidê para que enxuguem as mãos. 
Resposta 1: Na verdade, a toalhinha que geralmente usamos para o bidê foi idealizada como toalhinha para os hóspedes. As duas deveriam ser colocadas no mesmo porta-toalhas. A toalha maior é usada por você e a menor (já que serve apenas para enxugar as mãos) para a visita. Obviamente, muita gente não sabe disso, e mesmo aqueles que sabem, não utilizam a toalhinha de maneira correta. Aliás, eu mesma, quando vou à casa de alguém, evito usar a toalha pequena, mesmo quando é colocada no mesmo porta-toalhas, porque tenho medo que a toalha pequena seja usada para enxugar outras partes.

Resposta 2: A toalha de bidê não é chamada ospite. A toalha que chamamos assim é um pouco menor do que aquela que, geralmente, é usada pelos donos da casa. É denominada ospite porque, normalmente, para as visitas, usa-se uma toalha que ninguém usa.

Disponível em:

http://it.answers.yahoo.com/question/index?qid=20091005020611AATislm (Acesso em 02 de junho de 2012)

Este exemplo comprova que as inferências - não apenas sobre as palavras -, mas também sobre os elementos extralinguísticos, dependem do conhecimento de mundo.

A competência linguística pressupõe a competência intercultural porque a língua e, portanto, o léxico são componentes do macroconjunto denominado cultura. Um dicionário para aprendizes não pode apenas traduzir <toalha> por <asciugamano> e <tovaglia>, deve considerar as diferenças que existem no nível extralinguístico e que podem ser explicitadas na definição de cada uma das unidades lexicais.

Os aspectos extralinguísticos compreendem, também, os elementos não verbais presentes no discurso: ${ }^{1}$

Alguns componentes da comunicação são manifestados de uma maneira bastante explícita. Outros permanecem tácitos, ou seja, implícitos. [...] Na comunicação humana é impossível explicitar todos os aspectos. (SCOLLON, SCOLLON e JONES, 2012, p. 38 - 39)

O trabalho da elaboração de equivalências para um dicionário bilíngue para aprendizes vale-se das definições e de todo o trabalho lexicográfico realizado pelas equipes dos dicionários já existentes. A grande tarefa do lexicógrafo pedagógico bilíngue, no entanto, consiste em questionar as inferências automáticas que um aluno brasileiro faria em contato com a língua italiana e apresentar - por meio de definições, exemplos, ou imagens - os sememas distintivos para favorecer a comunicação intercultural e ajudá-lo a superar o choque cultural.

\footnotetext{
${ }^{1}$ São infinitos os aspectos extralinguísticos que influenciam a comunicação intercultural. Para aprofundamento, remetemos aos trabalhos de LOBASSO, PAVAN e CAON, 2007 e HALL, 1976.

Revista Italiano UERJ

Vol. $4-n^{\circ} 4-2013$

p. 6
} 


\section{O dicionário pedagógico}

O enfoque de nossa pesquisa é o aluno brasileiro que aprende a língua italiana e que se prepara para a comunicação intercultural. Nesse caso, não podemos agir sobre o falante nativo com o qual o nosso aluno irá interagir. O nosso objetivo, portanto, é ajudar o aluno a desenvolver a sua competência comunicativa intercultural que implica, inclusive, no conhecimento das regras do sistema linguístico usado para comunicar (léxico, fonética, ortografia, morfossintaxe etc.), mas, sobretudo, na capacidade de compreender a dificuldade do outro no momento da comunicação e intervir para eventuais ajustes.

O falante competente comunicativamente compreende que a língua traduz uma visão de mundo única e que o sistema linguístico e o léxico - parte desse sistema linguístico traduzem em signos os hábitos, as crenças, os valores, as regras, os conhecimentos e tudo o que distingue o modo de vida de um grupo social.

A competência comunicativa intercultural é um processo constante de autoconhecimento e de abertura à outra cultura. Ao buscar, em um dicionário pedagógico, os correspondentes em uma língua estrangeira para falar de si mesmo, o aluno encontrará uma realidade nova que compreende novos aspectos linguísticos, novas soluções comunicativas e, acima de tudo, uma nova visão de mundo, expressa pelos equivalentes encontrados. Ao produzir o seu texto, o aluno terá consciência do modo como o seu interlocutor apreenderá a mensagem contida na escolha lexical e, de maneira consciente, poderá diminuir os ruídos na comunicação.

O conceito "intercultural" significa que os indivíduos negociam os sentidos até se chegar à compreensão mais profunda e verdadeira possível dos sentidos atribuídos à linguagem/língua dos interlocutores. Ser-se intercultural significa ter-se adquirido competências de interação e reflexão, assim como de análise relativamente a essa interação. Desta análise, nasce a capacidade de se relativizarem dados (fossilizados e) estereotipados que possam impedir a comunicação. Também inclui a necessidade de mediação entre os dois falantes intervenientes para que as identidades culturais, sociais e políticas de ambos não se imiscuam como obstáculos na comunicação. Esta mediação torna-se tanto mais necessária quanto mais os interlocutores se identificarem com as suas culturas de origem e assumirem os seus totens como verdades absolutas. $\mathrm{O}$ falante interculturalmente competente ouve proativamente, isto é, facilitando a construção de pontes de comunicação, manifestando curiosidade autêntica, levando assim a que o seu interlocutor se sinta valorizado. O genuíno interesse manifestado pelo falante interculturalmente competente poderá ter como consequência que este questione as suas próprias crenças e valores à luz do que ouviu. A 
competência de reavaliação sistemática dos nossos imponderáveis permite uma maior flexibilidade e variedade de perspectivas sobre o mundo, embora possa ter como consequência algum "desassossego" cultural e mesmo psicológico, pois o sujeito pode ser levado a confrontar-se e reposicionar-se em termos identitários profundos. (BARROCAS, 2008, p. 8)

Assim como a competência cultural não é um conjunto fechado que pode ser adquirido em sua totalidade, o dicionário não é capaz de fornecer todos os exemplos de equivalências, usos e contextos culturais, mas pode indicar ao aluno que equivalentes absolutos só seriam possíveis se todos os sememas que compõem o significado da unidade lexical na língua 1 tivessem um correspondente na língua 2, e vice-versa. Além disso, o dicionário deveria trazer informações que evitassem a inferência automática de equivalências.

\section{"Era uma casa muito engraçada": o campo semântico da habitação}

Por meio da pergunta: "quais as diferenças entre a casa estrangeira e a casa brasileira/italiana?" Observaram-se algumas percepções de brasileiros e italianos sobre a própria habitação em viagens ao exterior. As declarações são sempre frutos da percepção subjetiva e note-se que o objetivo da pergunta não é apenas verificar as diferenças entre as casas brasileiras e italianas, mas a percepção que se tem da própria casa em relação àquelas visitadas em outros países. Quando uma mesma percepção é encontrada em várias respostas, podemos considerá-la como uma constatação compartilhada. Por exemplo, 25 brasileiros citaram a presença de banheira como uma característica das casas estrangeiras e 28 italianos mencionaram a falta de bidê nas casas estrangeiras.

Alguns participantes informam que não há diferenças entre as soluções habitacionais nas duas culturas, outros declaram terem consciência de que cada país encontra soluções específicas para a sua realidade:

La domanda è assurda, perchè nel mondo ci sono situazioni diversissime. (informante italiano166)

Le case sono diverse in ogni paese perché rispettano la cultura delle persone che la vivono. Ogni paese ha abitudini diverse, ritmi diversi, esigenze e priorità diverse. (informante italiano $\mathrm{n}^{\circ}$ 90)
É uma pergunta absurda, porque no mundo há situações muito diferentes.

As casas são diferentes em cada país porque respeitam a cultura das pessoas que vivem a casa. Cada país tem costumes diversos, ritmos diversos, exigências e prioridades diversas. 
Acho que a casa brasileira não tem uma característica única, pois varia muito de acordo com o nível social e o tamanho e necessidades da família (informante brasileiro $n^{\circ} 126$ ). Outros, ainda, enumeram claramente as características das habitações de seu país, ou do país estrangeiro:

Io adoro viaggiare. Adoro viaggiare e conoscere cose nuove. E non c'è niente di meglio che viaggiare per ampliare le proprie conoscenze. E quando viaggio mi piace osservare tutto ciò che per me è diverso da quello che sono abituato a vedere. E, tra le tante cose che attirano la mia attenzione, una delle più evidenti è l'architettura e la forma delle case. Infatti lo stile degli edifici caratterizza ogni nazione, ed è facile indovinare di quale città si tratti solo osservando le case che la compongono. Così è facile scoprire se siamo in una tipica via di Parigi, o un vicolo italiano o in un quartiere di New York. Di conseguenza, fin dalla mia prima volta in Brasile, mi divertivo a osservare la diversità delle case brasiliane. [...] Andiamo allora a vedere in cosa sono diverse queste case. É ovvio che parlerò in generale, sia per quanto riguarda il Brasile che l'Italia, perché è ovvio che, per esempio, le case di Salvador di Bahia sono diverse da quelle di São Paulo, come quelle di Portovenere, in Liguria, sono diverse da quelle di Varese.

Ma a parte qualche luogo caratteristico, in linea di massima possiamo dire che le case hanno più o meno lo stesso stile. (informante italiano $\mathrm{n}^{\mathrm{o}} 6$ ) [grifo nosso]
Eu amo viajar. Amo viajar e conhecer coisas novas. E não há nada melhor do que viajar para ampliar os próprios conhecimentos. E quando viajo, gosto de observar tudo o que é diferente do que estou acostumado a ver. Entre as muitas coisas que me chamam a atenção, uma das mais evidentes é a arquitetura e a forma das casas. $\mathrm{Na}$ verdade, o estilo dos prédios caracteriza cada nação, e é fácil adivinhar de qual cidade se trata apenas observando as casas que a compõem. Portanto, é fácil descobrir se estamos em uma típica rua de Paris, ou em um beco italiano, ou em um bairro de Nova York. Por isso, desde a minha primeira vez no Brasil, me divertia observando a diversidade das casas brasileiras. [...] Vejamos, então, em que são diferentes essas casas. Obviamente falarei de modo geral, tanto em relação ao Brasil, quanto à Itália, porque, é claro que, por exemplo, as casas de Salvador, na Bahia, são diferentes das casas de São Paulo, como as de Portovenere, na Liguria, são diferentes das casas de Varese. No entanto, com exceção de alguns lugares característicos, podemos dizer que, em geral, as casas têm mais ou menos o mesmo estilo. 
O depoimento confirma que o estudo do léxico pode nos ajudar a compreender o que significa uma casa brasileira em nível hiperonímico. Há atributos distintivos que compõem a solução habitacional de cada país e que a caracterizam, mesmo não sendo compartilhados pela totalidade das habitações.

Para conhecer exteriormente as casas e prédios de qualquer cidade do mundo contamos hoje com a ferramenta street view do Google. Para conhecer o interior das casas e as soluções para a aparência, funcionalidade e importância de cada ambiente, é preciso conversar com seus habitantes:

A prima vista non si vedono tante differenze tra una casa italiana e brasiliana. Ma basta fare un giro con lo sguardo più attento per accorgersi di alcuni dettagli e curiosità:

1. Quando si entra in una casa italiana si notano due aspetti che non troviamo in una brasiliana: i cognomi degli abitanti sui campanelli e le caselle per la posta (anche in un condominio).

2. Per molti italiani, la cucina è lo spazio più vivibile della casa ed è il luogo ideale per ricevere le visite informali (amici e parenti).

3. In bagno non può mancare il bidé. $\mathrm{E}$ molti italiani non rinunciano neanche alla vasca da bagno.

4. È difficile trovare uno spazio solo per la lavanderia, anche se si abita in una casa grande. Di solito la lavatrice si trova in bagno o in cucina e se si deve fare il bucato a mano, si usa il lavandino/lavatoio o la vasca da bagno. Ho notato che nelle case più antiche era abitudine un lavatoio appena fuori casa.

5. $\mathrm{E}^{\prime}$ anche rarissimo trovare una casa un po' più moderna (dopo gli anni 80 ) con lo scarico a pavimento nel bagno o nella cucina.
À primeira vista, não se veem tantas diferenças entre uma casa italiana e uma casa brasileira. Mas basta dar uma olhada mais atenta para perceber alguns detalhes e curiosidades:

1. Quando se entra em uma casa italiana, notam-se dois aspectos que não encontramos em uma casa brasileira: os sobrenomes dos moradores nas campainhas e as caixas do correio (mesmo em um condomínio).

2. Para muitos italianos a cozinha é o ambiente mais utilizado da casa e é o local ideal para receber as visitas informais (amigos e parentes).

3. No banheiro não pode faltar o bidê, e muitos italianos não abrem mão nem da banheira.

4. É difícil encontrar um espaço reservado apenas para a área de serviço, mesmo quando se mora em uma casa grande. Geralmente a máquina de lavar fica no banheiro ou na cozinha e, para lavar alguma coisa à mão, utiliza-se a pia do banheiro ou a banheira. Observei que nas casas mais antigas, existe um tanque, perto da casa, do lado de fora.

5. É, também, muito raro achar uma casa um pouco mais moderna (depois dos anos 80) com um ralo no chão do banheiro ou da cozinha.

6. Com algumas exceções, pode-se pendurar 
6. Con alcune eccezioni si può stendere tranquilamente a roupa para secar na sacada tranquillamente la biancheria fuori dal (no terraço) em alguns condomínios italianos.

balcone in alcuni condomini italiani.

(informante italiano $\mathrm{n}^{\circ} 8$ )

Em outra pergunta, foi solicitado aos colaboradores para que indicassem os três ambientes e os três elementos que não podem faltar nas casas de brasileiros e italianos:
Un tavolo dove ci si possa riunire, una
Uma mesa para reunir as pessoas; uma cucina con tutto ciò che può servire (anche senza la lavastoviglie, ma il forno non può mancare), un divano comodo e fotografia della famiglia. (informante italiano $\mathrm{n}^{\circ} 44$ )
Un luogo per cucinare e per socializzare assieme. (informante italiano $n^{\circ} 82$ )
Un balcone con i fiori, non $\mathrm{mi}$ viene in mente altro! (informante italiano ${ }^{\circ} 162$ )
Pasta, bidè e sorriso. (informante italiano $\mathrm{n}^{\circ}$ cozinha com todo o necessário (mesmo sem uma lava-louças, mas o forno não pode faltar); um sofá confortável e fotografia da família.
Um lugar para cozinhar e para socializar.
Uma sacada com flores, não me lembro de mais nada!
Macarrão, bidê e sorriso.
17)

Cozinha, quarto e banheiro. O conceito de casa brasileira muda muito entre quem mora na capital e quem mora no interior... (informante brasileiro $\mathrm{n}^{\circ} 148$ )

Apetrechos de preparar café, de preparar caipirinha, espaço para receber pessoas. (informante brasileiro $\mathrm{n}^{\circ} 330$ )

Arroz e feijão, um ambiente onde a família passe tempo junto e animais de estimação. (informante brasileiro $n^{\circ} 309$ )

Espaço para reunir a família e amigos; ar-condicionado/ventilador; espaços confortáveis, para que ficar em casa seja uma coisa boa. (informante brasileiro no 315 )

Espaço social onde as pessoas possam sentar e conversar. (informante brasileiro $\mathrm{n}^{\circ}$ 246)

As respostas dos informantes italianos indicam que o banheiro é o ambiente mais importante. Dos 268 participantes que o consideram um dos três ambientes mais importantes, nove o colocaram em primeiro lugar na lista de suas três escolhas (por ex. bagno, cucina e camera) e quatro especificaram que se trata de um bagno con bidet e doccia. A cozinha vem em segundo lugar em número de citações (176), mas por 134 vezes aparece em primeiro lugar na 
lista de cada indivíduo (por ex. cucina, bagno, camera); 16 especificaram que deve ser uma cucina abitabile, ou seja, com mesa e cadeiras, e um colaborador comentou que pode ser uma cucina abitabile o sala da pranzo, evidenciando, mais uma vez, a importância do convívio no momento das refeições.

Quando perguntados sobre as três coisas que não podem faltar em uma casa italiana, os participantes citaram a televisão em primeiro lugar (78), um dos informantes lamentou esse fato (TV (purtroppo)); em segundo lugar está a máquina de lavar roupas (50). A palavra "eletrodomésticos" foi citada por quatro pessoas. O conjunto de elementos mais citado, no entanto, é relativo ao ambiente da cozinha. A cozinha (cucina) foi citada por 28 colaboradores e seus móveis e utensílios somam 190 citações. A geladeira (frigorifero ou frigo) recebeu 41 citações, sendo que um colaborador especificou que deve ser um frigorifero capiente e con congelatore; o forno e o fogão obtiveram 21 e 30 citações respectivamente e podem ser considerados elementos fundamentais na casa italiana. A comida e o café também estão presentes entre os itens mais frequentes.

\section{Considerações finais}

As informações culturais - considerando as "diferenças culturais" como "soluções diversas para o mesmo problema" - não podem ser perdidas durante o trabalho lexicográfico, porque completam a definição. Em um dicionário para aprendizes, podemos usar vários recursos para inseri-las: exemplos, imagens, notas, vídeos ou depoimentos, cada um dos quais contribuindo para completar a definição lexicográfica.

Os três instrumentos empregados na pesquisa (depoimentos, questionários abertos e questionários eletrônicos) nos forneceram notas e exemplos para serem incluídos no verbete.

Empregar os depoimentos dos italianos que vivem no Brasil como exemplo no dicionário contribui para estabelecer um diálogo inicial com o aluno-consulente. $\mathrm{O}$ aluno brasileiro, que conhece a realidade da casa brasileira, reconhecerá, pelas palavras do estrangeiro, que existem traços distintivos entre as duas realidades que são observados pelos italianos e que ele, como nativo, não consegue reconhecer.

Os depoimentos dos brasileiros oferecerão ao consulente brasileiro instrumentos para sair do estado natural de cegueira cultural em que se encontra e questionar as suas próprias inferências automáticas. 
O falante comunicativamente competente é capaz de perceber quando ocorre uma falha na comunicação, detectar em qual nível essa falha ocorreu (linguístico - pronúncia, sintaxe, léxico - ou extralinguístico) e busca os meios para reparar a falha e recuperar a harmonia da comunicação, evitando que a interpretação equivocada das mensagens gere hostilidade.

O léxico e a escolha lexical são parte da competência linguística, assim como os elementos fonéticos, sintáticos, textuais e sociopragmáticos. A escolha lexical também colabora ou prejudica a comunicação intercultural; portanto, oferecer aos alunos instrumentos para utilizar o léxico corretamente contribui para a competência intercultural.

A pessoa comunicativamente competente tem os instrumentos para lidar com uma situação de conflito gerada pela incompreensão cultural. Destes instrumentos, o principal é a consciência de que mesmo uma situação de aparente equivalência pode ocultar diferenças de visões de mundo, crenças e rituais. Ao perceber que um conflito foi criado, pode-se verificar o ruído da comunicação e ajustá-la de modo a retomar o mais rapidamente possível o equilíbrio comunicativo.

A grande tarefa do lexicógrafo pedagógico bilíngue consiste em questionar as inferências automáticas que um aluno brasileiro faria em contato com a língua italiana e apresentar - por meio de definições, exemplos, ou imagens - os sememas distintivos para favorecer a comunicação intercultural. Ao lexicógrafo cabe, ainda, descobrir, dentre todos os traços distintivos, funcionais e não-funcionais que distinguem a unidade lexical, quais são os elementos relevantes e quais podem afetar o dia a dia do visitante estrangeiro e, desta forma, ajudar o comunicador intercultural a descobrir como evitar as armadilhas das inferências automáticas.

\section{Referências}

BACCIN, Paola. O dicionário bilíngue para aprendizes: uma ponte entre duas culturas. São Paulo, tese de livre-docência, FFLCH-USP, 2012.

BARROCAS, Ana Paula Borralho de Gouveia. O desenvolvimento da competência comunicativa intercultural no ensino secundário através do texto literário em inglês. Lisboa: [s. n.], 2008. v, 60, [34] f.. Trabalho de projeto de mestrado, Ensino do Inglês, 2008, FCSH-UNL.

HALL, Edwar T. Beyond Culture. New York: Anchor Books, 1976.

Revista Italiano UERJ

Vol. 4 - n 4 - 2013 
LOBASSO, Fabrizio; PAVAN, Elisabetta; CAON, Fabio. Manuale di comunicazione interculturale tra italiani e greci. Perugia: Guerra, 2007.

HOUAISS, A. Dicionário Eletrônico Houaiss da Lingua Portuguesa. Instituto Antônio Houaiss. Rio de Janeiro: Editora Objetiva Ltda., 2009.

SCOLLON, Ron; SCOLLON, Suzanne Wong; JONES, Rodney H. Intercultural communication: a discourse approach. West-Sussex: Wiley-Blackwell, 2012. 